\title{
Intra and inter-rater reliability of infrared image analysis of masticatory and upper trapezius muscles in women with and without temporomandibular disorder
}

\author{
Confiabilidade intra e interexaminador da análise de imagens infravermelhas dos músculos \\ mastigatórios e trapézio superior em mulheres com e sem disfunção temporomandibular
}

\author{
Ana C. S. Costa, Almir V. Dibai Filho, Amanda C. Packer, \\ Delaine Rodrigues-Bigaton
}

\begin{abstract}
Background: Infrared thermography is an aid tool that can be used to evaluate several pathologies given its efficiency in analyzing the distribution of skin surface temperature. Objectives: To propose two forms of infrared image analysis of the masticatory and upper trapezius muscles, and to determine the intra and inter-rater reliability of both forms of analysis. Method: Infrared images of masticatory and upper trapezius muscles of 64 female volunteers with and without temporomandibular disorder (TMD) were collected. Two raters performed the infrared image analysis, which occurred in two ways: temperature measurement of the muscle length and in central portion of the muscle. The Intraclass Correlation Coefficient (ICC) was used to determine the intra and inter-rater reliability. Results: The ICC showed excellent intra and inter-rater values for both measurements: temperature measurement of the muscle length (TMD group, intra-rater, ICC ranged from 0.996 to 0.999 , inter-rater, ICC ranged from 0.992 to 0.999 ; control group, intra-rater, ICC ranged from 0.993 to 0.998 , inter-rater, ICC ranged from 0.990 to 0.998 ), and temperature measurement of the central portion of the muscle (TMD group, intra-rater, ICC ranged from 0.981 to 0.998 , inter-rater, ICC ranged from 0.971 to 0.998 ; control group, intra-rater, ICC ranged from 0.887 to 0.996 , inter-rater, ICC ranged from 0.852 to 0.996). Conclusion: The results indicated that temperature measurements of the masticatory and upper trapezius muscles carried out by the analysis of the muscle length and central portion yielded excellent intra and inter-rater reliability.
\end{abstract}

Keywords: physical therapy; temporomandibular joint disorder; reliability; thermography; skin temperature.

\section{HOW TO THE CITE ARTICLE}

Costa ACS, Dibai Filho AV, Packer AC, Rodrigues-Bigaton D. Intra and inter-rater reliability of infrared image analysis of masticatory and upper trapezius muscles in women with and without temporomandibular disorder. Braz J Phys Ther. 2013 JanFeb; 17(1): 24-31. http://dx.doi.org/10.1590/S1413-35552012005000058

RESUMO| Contextualização: A termografia infravermelha vem sendo utilizada como instrumento auxiliar na avaliação de patologias diversas, dada a sua eficiência na investigação da distribuição da temperatura superficial cutânea. Objetivos: Propor duas formas de análise das imagens infravermelhas dos músculos mastigatórios e trapézio superior e determinar a confiabilidade intra e interexaminador dessas duas formas de análise. Método: Foram coletadas imagens infravermelhas dos músculos mastigatórios e trapézio superior de 64 voluntárias do gênero feminino, com e sem disfunção temporomandibular (DTM). A análise das imagens infravermelhas ocorreu de duas formas: mensuração da temperatura da extensão do músculo e do centro do músculo, sendo realizada por dois examinadores. A confiabilidade intra e interexaminador foi verificada por meio do Coeficiente de Correlação Intraclasse (CCI). Resultados: Os valores do CCI intra e interexaminador foram considerados excelentes em ambas as avaliações: análises da extensão do músculo (grupo DTM, intraexaminador, CCI variou de 0,996 a 0,999, interexaminador, CCI variou de 0,992 a 0,999; grupo controle, intraexaminador, CCI variou de 0,993 a 0,998, interexaminador, CCI variou de 0,990 a 0,998 ) e análise do centro do músculo (grupo DTM, intraexaminador, CCI variou de 0,981 a 0,998, interexaminador, CCI variou de 0,971 a 0,998; grupo controle, intraexaminador, CCI variou de 0,887 a 0,996 , interexaminador, $\mathrm{CCI}$ variou de 0,852 a 0,996 ). Conclusão: $\mathrm{O}$ estudo evidenciou que a mensuração da temperatura dos músculos mastigatórios e trapézio superior, realizada por meio da análise da extensão e do centro do músculo, apresentou excelente confiabilidade intra e interexaminador.

Palavras-chave: fisioterapia; transtornos da articulação temporomandibular; reprodutibilidade dos testes; termografia; temperatura cutânea. 


\section{- Introduction}

Blood flow towards the skeletal muscles is directly related to the contraction or relaxation state of the muscle supplying oxygen and nutrients to the muscles so it can function perfectly ${ }^{1}$. Most of the energy supplied to the muscles generates heat. Therefore, with a rigid central control, the body temperature remains at approximately $37^{\circ} \mathrm{C}$, and consequently, chemical reactions are processed and homeostasis is maintained ${ }^{2}$.

The measurement of the central body temperature is one of the methods commonly used in clinical practice for the diagnosis and monitoring of feverish states $^{3}$. To measure the peripheral temperature, the infrared thermography is applied. It is based on the emission of body infrared radiation with a temperature above absolute zero, used as an effective tool for the diagnosis of various diseases, given its efficiency in analyzing the distribution of skin surface temperature ${ }^{4}$.

The infrared thermography can be used to measure the skin surface temperature of masticatory muscles and temporomandibular joint in individuals with temporomandibular disorder (TMD) ${ }^{5-9}$, which is defined as a multifactor pathology, difficult to diagnose and characterized by an alteration of the masticatory muscles, limitation of the jaw movement, pain, joint noises and other symptoms ${ }^{10-12}$. In individuals with TMD, the temperature is altered when the blood flow decreases in the masticatory muscles due to a mechanical compression of blood vessels as a result of the muscular hyperactivity ${ }^{9,10}$. It is important to evaluate various aspects of the masticatory muscles, such as temperature, due to the high prevalence of involvement of this component of the stomatognathic system in subjects with TMD ${ }^{13}$.

Some studies ${ }^{6,14-18}$ were carried out to assess the temperature of masticatory and upper trapezius muscles. In these investigations, a high level of subjectivity was observed in the infrared image analysis, even with the delimitation of specific areas to register the temperature. Therefore, new methods should be developed to allow a more objective analysis of such areas.

McCoy et al. ${ }^{19}$ performed a study with 100 healthy subjects, whose paravertebral muscles were submitted to thermography, using an infrared scanner. The authors observed that the paraspinal thermal scanning presented excellent reliability. In another study conducted by Hart et al. ${ }^{20}$, three examiners evaluated 30 healthy individuals using a paraspinal thermal scanning to evaluate three methods of computer-aided thermal pattern analysis. The authors observed that the results of the intra and inter-rater analyses for all methods were acceptable, which ensured the reliability of the three analyzed software. Varjú et al. ${ }^{21}$ evaluated 91 individuals with hand osteoarthritis and correlated the thermogram, $\mathrm{x}$-ray and digital photograph images, which presented high reliability. In a similar study, Spalding et al. ${ }^{22}$ analyzed the thermal and three-dimensional images of 17 individuals with hand arthritis and concluded that both images presented reliable measures, which showed that these technologies can be used to better quantify the disease diagnosis. Based on these studies, the hypothesis is that the infrared thermography is a reliable instrument to be used as an assessment method.

Although some studies have observed excellent reliability in the use of infrared thermography ${ }^{19,21-23}$, the literature on the reliability of infrared thermography in the evaluation of masticatory and upper trapezius muscles is scarce. Therefore, for the infrared thermography to be properly used, both in clinical and research practices, as an aid resource to assist in the diagnosis of TMD and to evaluate the effect of different therapeutic resources, it is necessary to evaluate the levels of intra and inter-rater reliability.

Therefore, the aim of the present study was to propose two forms of analyses of infrared images of masticatory and upper trapezius muscles, and to determine the intra and inter-rater reliability of both forms of analyses.

\section{Method}

\section{Sample}

The sample comprised of 64 female volunteers recruited through a verbal invitation in the university community of the city of Piracicaba, São Paulo, Brazil, being 32 with TMD (TMD group), average age of $25.63(\mathrm{SD}=3.85)$ years, mean body mass index (BMI) of $21.60(\mathrm{SD}=2.45) \mathrm{kg} / \mathrm{m}^{2}$, and 32 without TMD (control group), average age of $22.18(\mathrm{SD}=2.95)$ years, mean BMI of $21.18(\mathrm{SD}=2.14) \mathrm{kg} / \mathrm{m}^{2}$.

The Research Diagnostic Criteria for Temporomandibular Disorders (RDC/TMD) ${ }^{24}$ was used to select the volunteers without and with TMD (myofascial pain, Ia or Ib diagnosis).

The exclusion criteria were: women with BMI over $25 \mathrm{~kg} / \mathrm{m}^{2}$, in orthodontic treatment, using painkillers, anti-inflammatory or muscle relaxers. Volunteers with systemic disease, history of facial or cervical spine trauma, cervical discopathy and those diagnosed with TMD (IIIb or IIIc) through RDC/TMD criteria were also excluded.

The study procedures were approved by the Research Ethics Committee of the Universidade Medodista de Piracicaba (UNIMEP), Piracicaba, SP, 
Brazil, under protocol number 15/11. Each volunteer signed a consent form.

\section{Infrared thermography}

To evaluate the temperature of the right (RMA) and left masseter (LMA), right (RAT) and left anterior temporalis (LAT), right (RUT) and left upper trapezius (LUT) and supra-hyoid (SHY) muscles was used a thermal camera T360 model, FLIR Systems ${ }^{\circledR}$ (Stockholm, Sweden). The following parameters were considered: an emissivity of 0.98 and image captured at a $100 \mathrm{~cm}$ distance from the individual ${ }^{25}$. The instrument was stabilized for 10 minutes before the exam.

For the examination, the volunteers stayed in an acclimatized room (approximately $22{ }^{\circ} \mathrm{C}$ ) for 20 minutes, without the presence of electric heat generators and equipment without incidence of air or sunlight. Fluorescent bulbs lighted the place.

Two hours before data collection, the participants were asked to avoid hot showers or baths, to use of topical agents, creams or powders or nasal decongestants, to not practice vigorous exercise, or to intake stimulants such as caffeine.
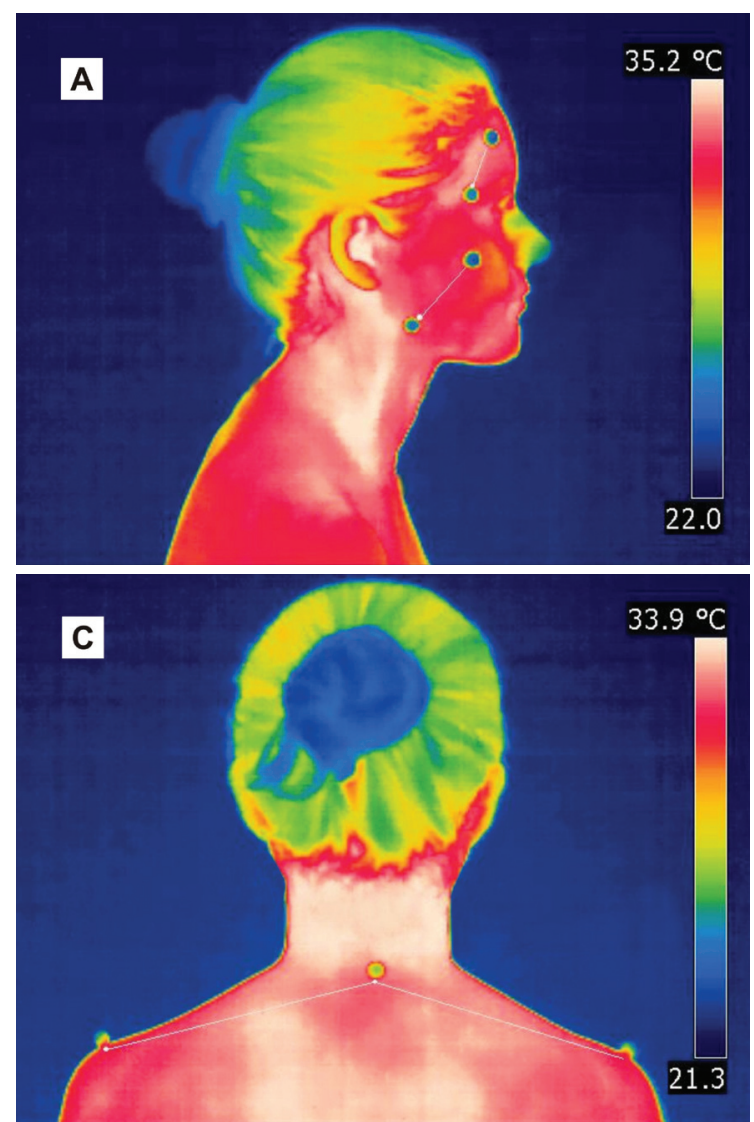

During data collection, the volunteers sat in a chair, with the trunk erect, feet on the ground and hands resting on the thighs, following the Frankfurt plane parallel to the ground. The region of the muscles to be assessed had to be free from clothes and personal items, such as earrings and necklaces; the hair had to be tied, whenever necessary.

Styrofoam markers were used due to their insulating characteristics, with the purpose of delimiting the origins and insertions of the evaluated muscles, enabling their further analysis in the infrared image.

For the anterior temporalis muscle, one marker was placed on the frontal bone, immediately above the muscle belly, and another near the eyelid lateral commissure; for the masseter muscle, one marker was positioned into the zygomatic arch and another in the lateral surface of the angle of mandible; for the supra-hyoid muscles, one marker was positioned on the ment and another on the hyoid bone; and for the upper trapezius muscle, one marker was positioned on the $\mathrm{C} 7$ spinous process and another on the acromion.

The infrared imaging analysis was performed in two ways: temperature measurement of the muscle length and central portion. All analyses were
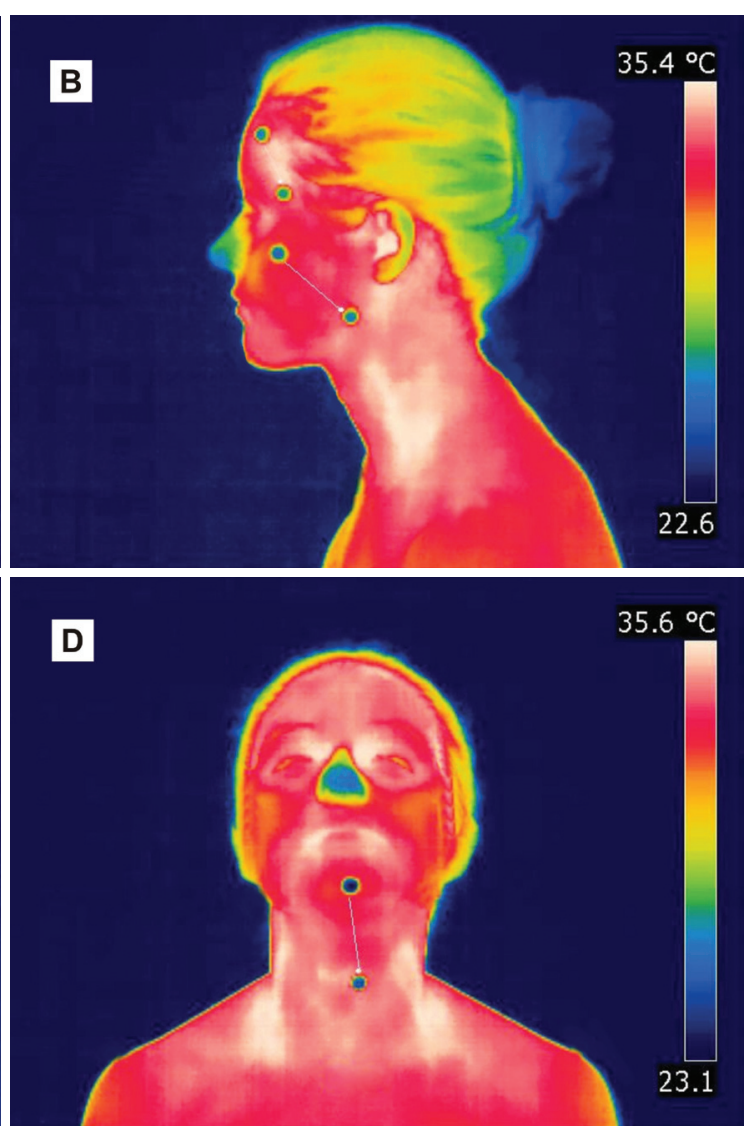

Figure 1. Analysis of infrared images by measuring the muscle length. Anterior temporalis and masseter (A and B), upper trapezius (C) and supra-hyoid (D) muscles. 

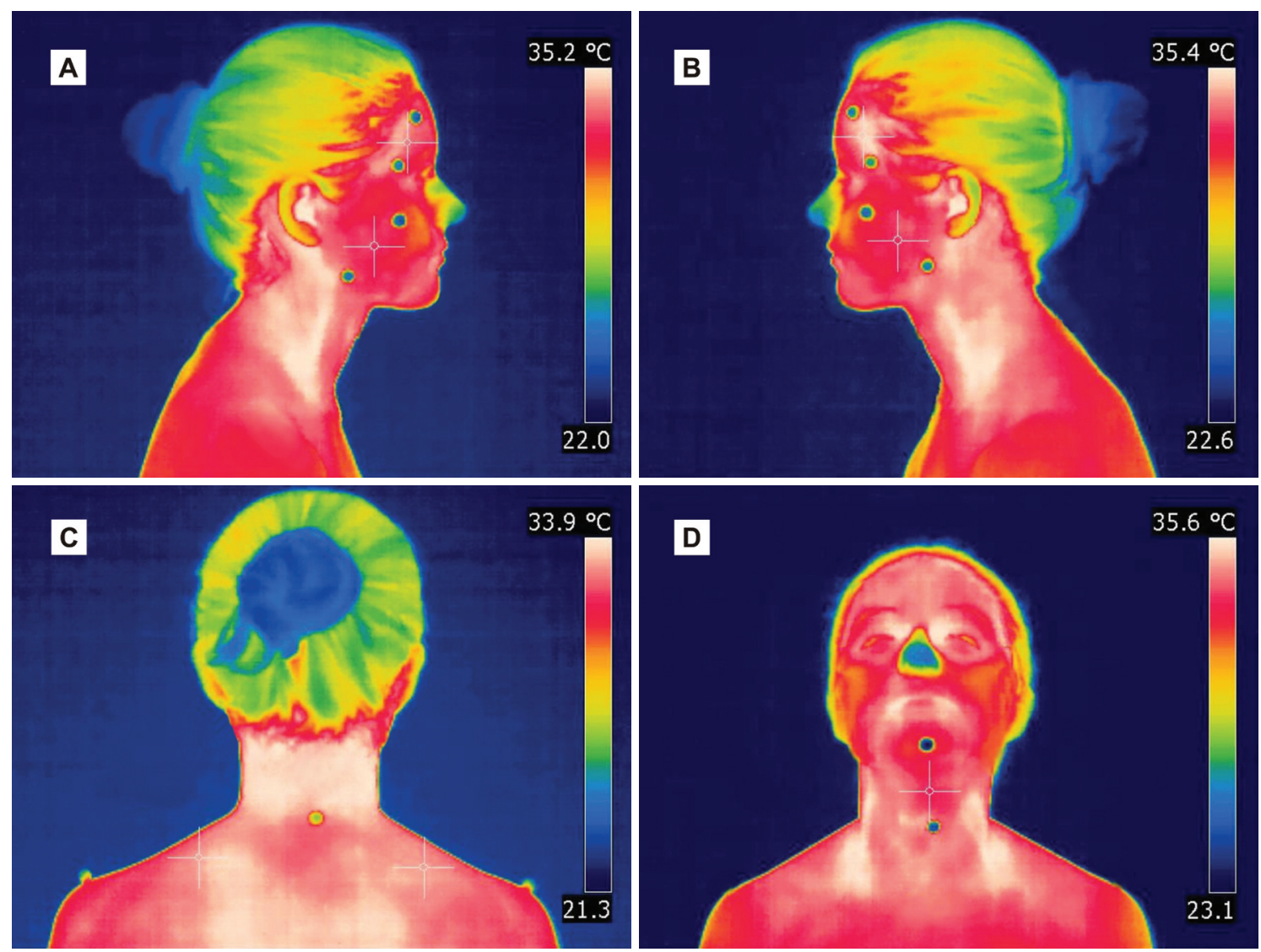

Figure 2. Analysis of infrared images by measuring the center portion of the muscle. Anterior temporalis and masseter (A and B), upper trapezius (C) and supra-hyoid (D) muscles.

performed by two raters using the QuickReport software, version 1.1, FLIR Systems ${ }^{\circledR}$ (Stockholm, Sweden).

\section{Analysis of muscle length temperature}

For this analysis, the "line" tool of the software was used with a line being drawn between the markers along the entire length of the delimited muscle, generating the average temperature of the entire line extension (Figure 1).

\section{Temperature analysis of the muscle central portion}

The "point" tool of the software determined the temperature value. Thus, a point on an average distance was set up between the markers and the central portion of the muscle was established (Figure 2).

\section{Reliability analysis}

Two trained raters evaluated three infrared images from each muscle, totaling 672 measurements for each type of analysis (muscle length and center portion).

To evaluate the intra-rater reliability, a single rater analyzed the images in two different occasions separated by a one-week interval ${ }^{26}$. For the inter-rater reliability, two independent examiners analyzed the same images.

In addition, a reliability evaluation was carried out between the analyses: for the intra-rater, an examiner measured the infrared image temperature by analyzing the muscle length and the center portion of the muscle; for the inter-rater, an examiner measured the temperature by analyzing the muscle length, while the other measured it by analyzing the center portion of the muscle.

\section{Statistical analysis}

The Intraclass Correlation Coefficient (ICC) was used to determine the intra and inter-rater reliability, with its respective $95 \%$ confidence interval. Interpretation of ICC values was based on that suggested by Weir ${ }^{27}$. For values ranging from 1.0 to 0.81 , the reliability was considered excellent; 
from 0.80 to 0.61 , very good; from 0.60 to 0.41 , good; from 0.40 to 0.21 , reasonable and, finally, from 0.20 to 0.00 , poor. The statistical analysis was performed using the SPSS $^{\circledR}$ software, version 13.0 (Chicago, USA).

\section{Results}

For the TMD group, in the analysis of muscle length, we found the following mean values $(95 \%$ confidence interval) of skin surface temperature for each muscle evaluated: LMA, 32.84 (32.60 to 33.08); RMA, 32.99 (32.77 to 33.21); LTA, 34.09 (33.88 to 34.30); RTA, 34.29 (34.10 to 34.49); SHY, 32.99 (32.72 to 33.25); LUT, 32.60 (32.03 to 33.16); RUT, 32.67 (32.16 to 33.18). Furthermore, in the analysis of the muscle central portion, it was observed the following values: LMA, 32.99 (32.74 to 33.24); RMA, 33.03 (32.80 to 33.26); LTA, 34.08 (33.86 to 34.30); RTA, 34.32 (34.13 to 34.51); SHY, 33.05 (32.76 to 33.34); LUT, 33.00 (32.54 to 33.91); RUT, 32.85 (31.95 to 33.55$)$.

Table 1. Reliability analysis of infrared images by measuring the muscle length in the temporomandibular disorder (TMD) and control groups.

\begin{tabular}{|c|c|c|c|c|c|}
\hline \multirow{2}{*}{ Group } & \multirow{2}{*}{ Muscle } & \multicolumn{2}{|c|}{ Intra-rater } & \multicolumn{2}{|c|}{ Inter-rater } \\
\hline & & ICC & $95 \% \mathrm{CI}$ & ICC & $95 \% \mathrm{CI}$ \\
\hline \multirow[t]{7}{*}{ TMD } & LMA & $0.999 *$ & 0.998-0.999 & $0.995^{*}$ & 0.993-0.997 \\
\hline & LAT & $0.997 *$ & $0.996-0.998$ & $0.992 *$ & $0.988-0.995$ \\
\hline & RMA & $0.999 *$ & 0.998-0.999 & $0.999 *$ & 0.998-0.999 \\
\hline & RAT & $0.996 *$ & 0.994-0.998 & $0.994 *$ & $0.990-0.996$ \\
\hline & SHY & $0.998^{*}$ & 0.997-0.999 & $0.999 *$ & 0.998-0.999 \\
\hline & LUT & $0.999 *$ & 0.998-0.999 & $0.997 *$ & $0.995-0.998$ \\
\hline & RUT & $0.999 *$ & 0.998-0.999 & $0.998 *$ & 0.997-0.998 \\
\hline \multirow[t]{7}{*}{ Control } & LMA & $0.998^{*}$ & 0.997-0.999 & $0.998 *$ & 0.993-0.998 \\
\hline & LAT & $0.998^{*}$ & 0.997-0.999 & $0.992 *$ & $0.988-0.995$ \\
\hline & RMA & $0.998^{*}$ & 0.998-0.999 & $0.998^{*}$ & 0.998-0.999 \\
\hline & RAT & $0.996^{*}$ & 0.994-0.997 & $0.990 *$ & $0.990-0.996$ \\
\hline & SHY & $0.993 *$ & $0.990-0.995$ & $0.999 *$ & 0.998-0.999 \\
\hline & LUT & $0.998 *$ & 0.998-0.999 & $0.996^{*}$ & $0.995-0.998$ \\
\hline & RUT & $0.998 *$ & 0.998-0.999 & $0.998^{*}$ & $0.997-0.998$ \\
\hline
\end{tabular}

ICC: Intraclass Correlation Coefficient; CI: Confidence interval; LMA: Left masseter; LAT: Left anterior temporalis; RMA: Right masseter; RAT: Right anterior temporalis; SHY: Supra-hyoid; LUT: Left upper trapezius; RUT: Right upper trapezius; *Statistically significant ( $\mathrm{p}<0.0001)$.

Table 2. Reliability analysis of infrared images by measuring the central portion of the muscle in the TMD and control groups.

\begin{tabular}{|c|c|c|c|c|c|}
\hline \multirow{2}{*}{ Group } & \multirow{2}{*}{ Muscle } & \multicolumn{2}{|c|}{ Intra-rater } & \multicolumn{2}{|c|}{ Inter-rater } \\
\hline & & ICC & $95 \% \mathrm{CI}$ & ICC & $95 \% \mathrm{CI}$ \\
\hline \multirow[t]{7}{*}{ TMD } & LMA & $0.998^{*}$ & $0.997-0.999$ & $0.971 *$ & $0.957-0.981$ \\
\hline & LAT & $0.990 *$ & 0.985-0.993 & $0.984 *$ & 0.976-0.900 \\
\hline & RMA & $0.981 *$ & $0.972-0.987$ & $0.997 *$ & 0.996-0.998 \\
\hline & RAT & $0.988^{*}$ & $0.982-0.992$ & $0.983 *$ & 0.975-0.989 \\
\hline & SHY & $0.998 *$ & 0.998-0.999 & $0.998 *$ & 0.997-0.999 \\
\hline & LUT & $0.995^{*}$ & 0.993-0.997 & $0.992 *$ & $0.988-0.995$ \\
\hline & RUT & 0.994* & $0.991-0.996$ & $0.994 *$ & $0.991-0.996$ \\
\hline \multirow[t]{7}{*}{ Control } & LMA & $0.996^{*}$ & 0.994-0.999 & $0.996^{*}$ & 0.993-0.997 \\
\hline & LAT & $0.887 *$ & $0.816-0.918$ & $0.852 *$ & $0.778-0.901$ \\
\hline & RMA & $0.919 *$ & $0.878-0.946$ & $0.925^{*}$ & $0.887-0.950$ \\
\hline & RAT & $0.965^{*}$ & 0.948-0.997 & $0.924 *$ & $0.886-0.949$ \\
\hline & SHY & $0.996^{*}$ & 0.993-0.997 & $0.996^{*}$ & 0.994-0.997 \\
\hline & LUT & $0.994 *$ & 0.993-0.997 & $0.992 *$ & 0.988-0.995 \\
\hline & RUT & $0.995^{*}$ & $0.992-0.996$ & $0.994 *$ & 0.991-0.996 \\
\hline
\end{tabular}

ICC: Intraclass Correlation Coefficient; CI: Confidence interval; LMA: Left masseter; LAT: Left anterior temporalis; RMA: Right masseter; RAT: Right anterior temporalis; SHY: Supra-hyoid; LUT: Left upper trapezius; RUT: Right upper trapezius; *Statistically significant (p<0.0001). 
Table 3. Reliability between the infrared image analyses performed by measuring the temperature of the muscle length and central portion in the TMD and control groups. For the intra-rater analysis, the same examiner performed the measurements by analyzing both segments. For the inter-rater analysis, one examiner performed the measurements by analyzing the muscle length, while the other examiner, the central portion of the muscle.

\begin{tabular}{|c|c|c|c|c|c|}
\hline \multirow{2}{*}{ Group } & \multirow{2}{*}{ Muscle } & \multicolumn{2}{|c|}{ Intra-rater } & \multicolumn{2}{|c|}{ Inter-rater } \\
\hline & & ICC & $95 \% \mathrm{CI}$ & ICC & $95 \% \mathrm{CI}$ \\
\hline \multirow[t]{7}{*}{ TMD } & LMA & $0.958 *$ & $0.937-0.972$ & $0.989 *$ & 0.983-0.992 \\
\hline & LAT & $0.989 *$ & $0.984-0.993$ & $0.982 *$ & $0.973-0.988$ \\
\hline & RMA & $0.987 *$ & $0.981-0.991$ & $0.985^{*}$ & $0.977-0.990$ \\
\hline & RAT & $0.984 *$ & $0.976-0.989$ & $0.987 *$ & $0.981-0.992$ \\
\hline & SHY & $0.988 *$ & $0.982-0.992$ & $0.988^{*}$ & $0.982-0.992$ \\
\hline & LUT & $0.978^{*}$ & $0.966-0.985$ & $0.977 *$ & $0.966-0.985$ \\
\hline & RUT & $0.980^{*}$ & $0.970-0.987$ & $0.981 *$ & $0.971-0.987$ \\
\hline \multirow[t]{7}{*}{ Control } & LMA & $0.981 *$ & $0.971-0.987$ & $0.982 *$ & $0.973-0.988$ \\
\hline & LAT & $0.879 *$ & $0.819-0.920$ & $0.894 *$ & $0.841-0.929$ \\
\hline & RMA & $0.914 *$ & $0.870-0.942$ & $0.910^{*}$ & $0.865-0.940$ \\
\hline & RAT & $0.956^{*}$ & $0.934-0.971$ & $0.951 *$ & $0.926-0.967$ \\
\hline & SHY & $0.984 *$ & $0.977-0.990$ & $0.983^{*}$ & $0.974-0.988$ \\
\hline & LUT & $0.975^{*}$ & $0.966-0.985$ & $0.976^{*}$ & $0.966-0.985$ \\
\hline & RUT & $0.979 *$ & $0.970-0.987$ & $0.981 *$ & $0.971-0.987$ \\
\hline
\end{tabular}

ICC: Intraclass correlation coefficient; CI: Confidence interval; LMA: Left masseter; LAT: Left anterior temporalis; RMA: Right masseter; RAT: Right anterior temporalis; SHY: Supra-hyoid; LUT: Left upper trapezius; RUT: Right upper trapezius; *Statistically significant $(\mathrm{p}<0.0001)$.

For the control group, in the analysis of muscle length, the mean values (95\% confidence interval) of skin surface temperature for each muscle evaluated were: LMA, 32.67 (32.52 to 32.82); RMA, 32.65 (32.49 to 32.81); LTA, 34.22 (34.09 to 34.35); RTA, 34.21 (34.08 to 34.34 ); SHY, 33.02 (32.88 to 33.17 ); LUT, 32.59 (32.44 to 32.75); RUT, 32.57 (32.42 to 32.72). In the analysis of the muscle central portion, it was observed the following values: LMA, 32.77 (32.61 to 32.93); RMA, 32.69 (32.53 to 32.85); LTA, 34.31 (34.18 to 34.44); RTA, 34.17 (34.02 to 34.32); SHY, 33.17 (33.01 to 33.33); LUT, 32.94 (32.79 to 33.10); RUT, 32.91 (32.76 to 33.05).

The intra and inter-rater ICC values of the infrared image analysis of the muscle length and central portion are shown in Tables 1 and 2. The reliability was considered excellent in all analyses. The intra and inter-rater ICC values between the two types of infrared image analysis, muscle length and central portion, are shown in Table 3.

\section{Discussion}

The present study showed that the two types of infrared image analysis of masticatory and upper trapezius muscles showed excellent intra and interrater reliability. These results agreed with those by Owens et al. ${ }^{23}$, whose objective was to evaluate the paraspinal region by contact thermography. Other study ${ }^{19}$ obtained similar results to previous research ${ }^{23}$, providing evidence that the paraspinal thermal imaging is a reliable diagnostic test. The present study is not in agreement with previous ones in terms of the tool used to capture the images, which had no contact with the region being analyzed, keeping a $100 \mathrm{~cm}$ distance from the volunteers, while in the aforementioned studies ${ }^{19,23}$ the images were captured with the contact technique.

It is worthwhile to mention that in most studies the infrared image analysis is subjective, that is, the location for the evaluation of the muscle temperature is randomly determined ${ }^{6,8,14,16,28}$, while others studies make no reference to the way the analysis was carried out $^{5,29,30}$. Furthermore, no standardization of specific areas for image analysis was found in other studies that measure facial temperature ${ }^{31,32}$. With that regard, in the present study, the infrared image analysis was performed in two ways, muscle length and the central portion of the muscle, by using markers to delimit the muscle insertions and origins for further analysis. The reliability was considered excellent in all the analyses performed.

Therefore, considering the results found in this study, we recommend the use of infrared thermography as an aid tool in assessing TMD, mainly when the objective is to determine the effect of different therapeutic resources used for the TMD treatment, such as electrotherapy ${ }^{33,34}$, laser therapy ${ }^{35,36}$ and manual therapy ${ }^{37,38}$. 
The literature emphasizes the importance of using infrared thermography for the assessment and documentation of many pathologies ${ }^{39-42}$. However, for the adequate use of infrared thermography in TMD diagnosis, further studies should be carried out to evaluate the instrument accuracy.

The evaluation by the infrared thermography has some limitations, as the amount of subcutaneous fat, since this interferes in the skin surface temperature ${ }^{43}$. Furthermore, it is an indirect measure of the blood flow ${ }^{44}$ and of the activity of the autonomic nervous system $^{45}$. Thus, in this study, to ensure the quality of thermographic evaluation, women with BMI over $25 \mathrm{~kg} / \mathrm{m}^{2}$ were excluded, and remained for 20 minutes at $22{ }^{\circ} \mathrm{C}$ to ensure thermal equilibrium body.

Given the above, the limitation of this study referred to the non-evaluation of the variability of the measurements of temperature at different times of day, in different emotional states, and in different phases of the menstrual cycle.

\section{Conclusion}

The intra and inter-rater reliability of the temperature measures of the masseter, anterior temporalis, supra-hyoid and upper trapezius muscles analyzed by muscle length and central portion were considered excellent.

\section{Acknowledgements}

The Reginaldo Teixeira Coelho, Laboratory for Manufacturing Process Optimization, Engineering School of São Carlos, Universidade de São Paulo (USP), São Carlos, SP, Brazil.

\section{References}

1. Korthuis RJ. Skeletal muscle circulation. San Rafael: Morgan \& Claypool Life Sciences; 2011.

2. Kurz A. Physiology of thermoregulation. Best Pract Res Clin Anaesthesiol. 2008;22(4):627-44.

3. Kistemaker JA, Den Hartog EA, Daanen HA. Reliability of an infrared forehead skin thermometer for core temperature measurements. J Med Eng Technol. 2006;30(4):252-61.

4. Brioschi ML, Macedo JF, Macedo RAC. Skin thermography: new concepts. J Vasc Bras. 2003;2(2):151-60.

5. Canavan D, Gratt BM. Electronic thermography for the assessment of mild and moderate temporomandibular joint dysfunction. Oral Surg Oral Med Oral Pathol Oral Radiol Endod. 1995;79(6):778-86.

6. Pogrel MA, McNeill C, Kim JM. The assessment of trapezius muscle symptoms of patients with temporomandibular disorders by the use of liquid crystal thermography. Oral Surg Oral Med Oral Pathol Oral Radiol Endod. 1996;82(2):145-51.

7. Anbar M, Gratt BM. The possible role of nitric oxide in the physiopathology of pain associated with temporomandibular joint disorders. J Oral Maxillofac Surg. 1998;56(7):872-82

8. Anbar M, Gratt BM, Hong D. Thermology and facial telethermography. Part I: history and technical review. Dentomaxillofac Radiol. 1998;27(2):61-7.

9. Barão VAR, Gallo AKG, Zuim PRJ, Garcia AR, Assunção WG. Effect of occlusal splint treatment on the temperature of different muscles in patients with TMD. J Prosthodont Res. 2011;55(1):19-23.

10. Desmons S, Graux F, Atassi M, Libersa P, Dupas PH. The lateral pterygoid muscle, a heterogeneous unit implicated in temporomandibular disorder: a literature review. Cranio. 2007;25(4):283-91.

11. Bevilaqua-Grossi D, Chaves TC, Oliveira AS. Cervical spine signs and symptoms: perpetuating rather than predisposing factors for temporomandibular disorders in women. J Appl Oral Sci. 2007;15(4):259-64.

12. Stuginski-Barbosa J, Macedo HR, Bigal ME, Speciali JG. Signs of temporomandibular disorders in migraine patients: a prospective, controlled study. Clin J Pain. 2010;26(5):418-21.

13. Manfredini D, Guarda-Nardini L, Winocur E, Piccotti F, Ahlberg J, Lobbezoo F. Research diagnostic criteria for temporomandibular disorders: a systematic review of axis I epidemiologic findings. Oral Surg Oral Med Oral Pathol Oral Radiol Endod. 2011;112(4):453-62.

14. Morimoto T, Takada K, Hijiya H, Yasuda Y, Sakuda M. Changes in facial skin temperature associated with chewing efforts in man: a thermographic evaluation. Arch Oral Biol. 1991;36(9):665-70.

15. Gratt BM, Sickles EA. Thermographic characterization of the asymptomatic temporomandibular joint. J Orofac Pain. 1993;7(1):7-14.

16. Gratt BM, Sickles EA, Wexler CE, Ross JB Thermographic characterization of internal derangement of the temporomandibular joint. J Orofac Pain. 1994;8(2):197-206.

17. Gratt BM, Sickles EA, Wexler CE. Thermographic characterization of osteoarthrosis of the temporomandibular joint. J Orofac Pain. 1993;7(4):345-53.

18. Gratt BM, Sickles EA, Ross JB, Wexler CE, Gornbein JA. Thermographic assessment of craniomandibular disorders: diagnostic interpretation versus temperature measurement analysis. J Orofac Pain. 1994;8(3):278-88.

19. McCoy M, Campbell I, Stone P, Fedorchuk C, Wijayawardana S, Easley K. Intra-examiner and interexaminer reproducibility of paraspinal thermography. PLoS One. 2011;6(2):e16535.

20. Hart J, Omolo B, Boone WR, Brown C, Ashton A. Reliability of three methods of computer-aided thermal pattern analysis. J Can Chiropr Assoc. 2007;51(3):175-85.

21. Varjú G, Pieper CF, Renner JB, Kraus VB. Assessment of hand osteoarthritis: correlation between thermographic and radiographic methods. Rheumatology (Oxford). 2004;43(7):915-9. 
22. Spalding SJ, Kwoh CK, Boudreau R, Enama J, Lunich $\mathrm{J}$, Huber D, et al. Three-dimensional and thermal surface imaging produces reliable measures of joint shape and temperature: a potential tool for quantifying arthritis. Arthritis Res Ther. 2008;10(1):R10.

23. Owens EF Jr, Hart JF, Donofrio JJ, Haralambous J, Mierzejewski E. Paraspinal skin temperature patterns: an interexaminer and intraexaminer reliability study. J Manipulative Physiol Ther. 2004;27(3):155-9.

24. Dworkin SF, LeResche L. Research diagnostic criteria for temporomandibular disorders: review, criteria, examinations and specifications, critique. J Craniomandib Disord. 1992;6(4):301-55.

25. Hakgüder A, Birtane M, Gürcan S, Kokino S, Turan FN. Efficacy of low level laser therapy in myofascial pain syndrome: an algometric and thermographic evaluation. Lasers Surg Med. 2003;33(5):339-43.

26. Van Maanen CJ, Zonnenberg AJ, Elvers JW, Oostendorp RA. Intra/interrater reliability of measurements on body posture photographs. Cranio. 1996;14(4):326-31.

27. Weir JP. Quantifying test-retest reliability using the intraclass correlation coefficient and the SEM. J Strength Cond Res. 2005;19(1):231-40.

28. Vargas JVC, Brioschi ML, Dias FG, Parolin MB, MulinariBrenner FA, Ordonez JC, et al. Normalized methodology for medical infrared imaging. Infrared Phys Technol. 2009;52(1):42-7.

29. McBeth SB, Gratt BM. Thermographic assessment of temporomandibular disorders symptomology during orthodontic treatment. Am J Orthod Dentofacial Orthop. 1996;109(5):481-8.

30. Kopp S, Haraldson T. Skin surface temperature over the temporomandibular joint and masseter muscle in patients with craniomandibular disorder. Swed Dent J. 1988;12(1-2):63-7.

31. Berry DC, Yemm R. A further study of facial skin temperature in patients with mandibular dysfunction. J Oral Rehabil. 1974;1(3):255-64.

32. Tegelberg A, Kopp S. Skin surface temperature over the temporomandibular joint and masseter muscle in healthy children and adolescents. Acta Odontol Scand. 2002;60(5):271-5.

33. Gomes NCMC, Berni-Schwarzenbeck KCS, Packer AC, Rodrigues-Bigaton D. Effect of cathodal high-voltage electrical stimulation on pain in women with TMD. Rev Bras Fisioter. 2012;16(1):10-5.

34. Rodrigues-Bigaton D, Almeida AFN, Berni KCS, Pedroni CR, Gonçalves RN, Bérzin F. Use of different electrical stimulations for treating pain in women with temporomandibular disorders. Rev Bras Fisioter. 2008;12(6):476-81.

35. Frare JC, Nicolau RA. Clinical analysis of the effect of laser photobiomodulation (GaAs - $904 \mathrm{~nm}$ ) on temporomandibular joint dysfunction. Rev Bras Fisioter. 2008;12(1):37-42.

36. Petrucci A, Sgolastra F, Gatto R, Mattei A, Monaco A. Effectiveness of low-level laser therapy in temporomandibular disorders: a systematic review and meta-analysis. J Orofac Pain. 2011;25(4):298-307.

37. Von Piekartz H, Lüdtke K. Effect of treatment of temporomandibular disorders (TMD) in patients with cervicogenic headache: a single-blind, randomized controlled study. Cranio. 2011;29(1):43-56.

38. Oliveira-Campelo NM, Rubens-Rebelatto J, MartínVallejo FJ, Alburquerque-Sendín F, Fernández-de-LasPeñas C. The immediate effects of atlanto-occipital joint manipulation and suboccipital muscle inhibition technique on active mouth opening and pressure pain sensitivity over latent myofascial trigger points in the masticatory muscles. J Orthop Sports Phys Ther. 2010;40(5):310-7.

39. Ring F. Thermal imaging today and its relevance to diabetes. J Diabetes Sci Technol. 2010;4(4):857-62.

40. Denoble AE, Hall N, Pieper CF, Kraus VB. Patellar skin surface temperature by thermography reflects knee osteoarthritis severity. Clin Med Insights Arthritis Musculoskelet Disord. 2010;3:69-75.

41. Fikackova H, Ekberg E. Can infrared thermography be a diagnostic tool for arthralgia of the temporomandibular joint? Oral Surg Oral Med Oral Pathol Oral Radiol Endod. 2004;98(6):643-50.

42. Sefton JM, Yarar C, Berry JW, Pascoe DD. Therapeutic massage of the neck and shoulders produces changes in peripheral blood flow when assessed with dynamic infrared thermography. J Altern Complement Med. 2010;16(7):723-32.

43. Savastano DM, Gorbach AM, Eden HS, Brady SM, Reynolds JC, Yanovski JA. Adiposity and human regional body temperature. Am J Clin Nutr. 2009;90(5):1124-31.

44. Seifalian AM, Stansby G, Jackson A, Howell K, Hamilton G. Comparison of laser Doppler perfusion imaging, laser Doppler flowmetry, and thermographic imaging for assessment of blood flow in human skin. Eur J Vasc Surg. 1994;8(1):65-9.

45. Holey LA, Dixon J, Selfe J. An exploratory thermographic investigation of the effects of connective tissue massage on autonomic function. J Manipulative Physiol Ther. 2011;34(7):457-62.

\section{Correspondence}

\section{Almir Vieira Dibai Filho}

Rua São João, 1529

Ed. Saint Michael, apto 62, Bairro Alto

CEP 13416-585, Piracicaba, SP, Brasil

e-mail: dibaifilho@gmail.com 